\section{How to approach}

\section{hypercalcaemia}

Rachel Crowley, ${ }^{1,2}$ clinical research fellow; Neil Gittoes, ${ }^{1,2}$ consultant endocrinologist

${ }^{1}$ University Hospitals Birmingham NHS

Foundation Trust; ${ }^{2}$ University of

Birmingham, UK

\section{Background}

Mild hypercalcaemia is common and is often detected as a coincidental observation on blood testing for an unrelated reason. Severe hypercalcaemia, usually considered to be a serum calcium measurement of $>3.5 \mathrm{mmol} / \mathrm{l}$, is a medical emergency with life-threatening consequences. It is important for clinicians in primary, secondary and emergency care to be familiar with the diagnosis, management and underlying causes of hypercalcaemia. There is an initial 'uniform' approach to the treatment of acute severe hypercalcaemia (of all causes), but the underlying cause of the hypercalcaemia must be established to provide optimal longer-term management. A clear understanding of physiological calcium regulation along with a handful of associated and relevant blood test results allows determination of the underlying cause of hypercalcaemia in all but the most idiosyncratic cases.

\section{Control of serum calcium}

Maintenance of normal calcium levels is under tight regulation by parathyroid hormone (PTH) and vitamin D (Fig 1). ${ }^{1}$ PTH is secreted by the parathyroid glands and its overall effect is to increase serum calcium and activated vitamin $\mathrm{D}$, and to lower phosphorus levels. ${ }^{1}$ The calciumsensing receptor (CaSR) on parathyroid cells is activated by extracellular calcium to inhibit PTH release. ${ }^{2}$ Vitamin D is synthesised from cholesterol in the skin in response to sunlight and activated in the liver to 25 hydroxyvitamin D (25-OHD), and in the kidney to the active form 1,25 dihydroxyvitamin D $\left(1,25-(\mathrm{OH})_{2}\right.$ vitamin D). ${ }^{1}$ Calcitonin is

Parathyroid Glands

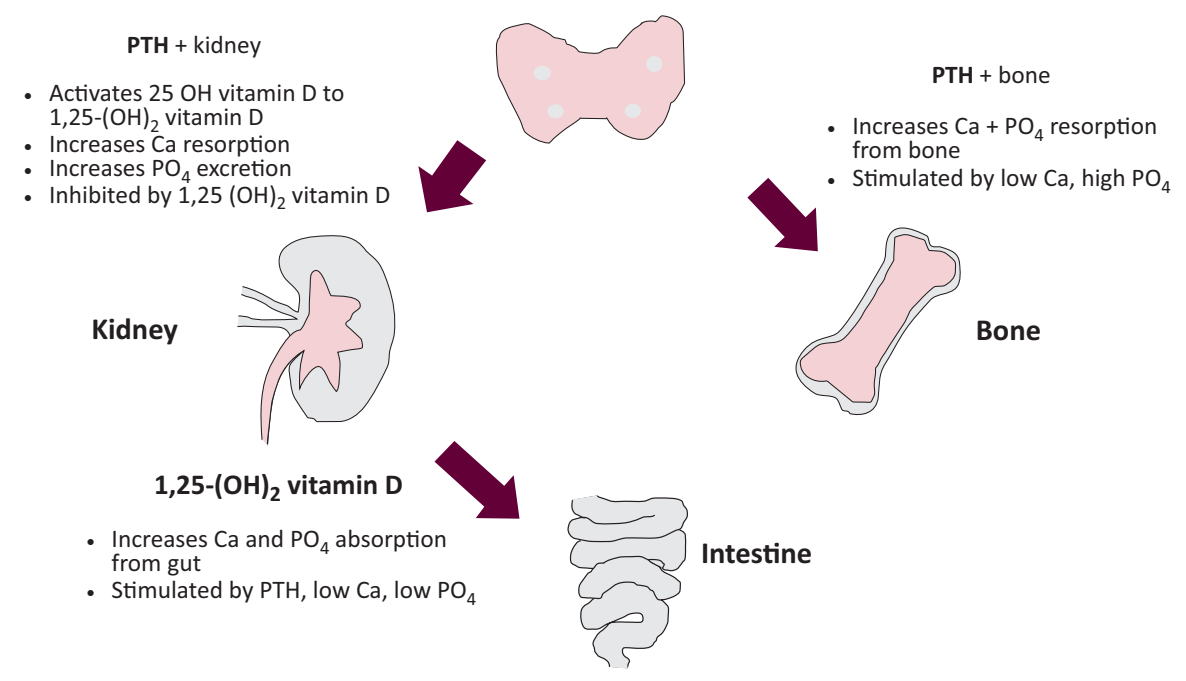

Fig 1. Calcium homeostasis. End organ effects of parathyroid hormone (PTH) and vitamin $\mathrm{D}\left(1,25(\mathrm{OH})_{2}\right.$ vitamin $\left.\mathrm{D}\right) .1,25-(\mathrm{OH})_{2} \mathrm{D}=$ active vitamin $\mathrm{D} ; \mathrm{Ca}=$ calcium; $\mathrm{PO}_{4}=$ phosphate; PTH = parathyroid hormone.

produced by the $\mathrm{C}$ cells of the thyroid; it acts to inhibit osteoclast resorption and promotes calcium and phosphate excretion, but is of little relevance to hypercalcaemia clinically.

\section{Clinical presentation of hypercalcaemia}

Milder degrees of hypercalcaemia $(<3.0$ $\mathrm{mmol} / \mathrm{l}$ ) are usually not associated with symptoms if the rate of rise has been slow. Polyuria and polydipsia represent nephrogenic diabetes insipidus, ${ }^{3}$ while neurological and muscular manifestations of hypercalcaemia are due to increased depolarisation thresholds in cell membranes. Mild tiredness through to obtundation and coma represent the spectrum of neurological manifestations of hypercalcaemia. Owing to the lack of specificity of presenting clinical features of hypercalcaemia, it is necessary to have a high index of clinical suspicion and to request a measurement of serum (or ionised) calcium to establish the diagnosis.

Total serum calcium results should be adjusted for serum albumin: ${ }^{4}$

$$
\begin{aligned}
& \text { Adjusted calcium }(\mathrm{mmol} / \mathrm{l}) \\
& \quad=\text { serum calcium } \\
& +[(40-\text { plasma albumin in } \mathrm{g}) \times 0.02] \text {. }
\end{aligned}
$$

Worked example: for calcium $2.60 \mathrm{mmol} / \mathrm{l}$ and albumin $34 \mathrm{~g}$ :

adjusted calcium $=$

$$
\begin{aligned}
2.6 & +[(40-34=6) \times 0.02] \\
& =2.72 \mathrm{mmol} / \mathrm{l}
\end{aligned}
$$

It is not necessary to use adjustment if ionised calcium can be measured, but this is not available in all centres. Measurement of ionised calcium should be considered for patients with high calcium levels who are known to have circulating paraproteins, such as those with myeloma, because paraproteins interfere with calcium measurement. ${ }^{4}$

\section{Determining the cause of hypercalcaemia}

Primary hyperparathyroidism and malignancy account for around 90\% of cases of hypercalcaemia (Box 1). With this in mind, the first investigation in hypercalcaemia is measurement of PTH, which will distinguish between these two most common causes. There might be specific clinical features that help to distinguish benign and malignant causes of hypercalcaemia before a PTH result is available (Table 2). 


\section{Hypercalcaemia with elevated PTH}

In primary hyperparathyroidism, $\mathrm{PTH}$ is either frankly elevated or inappropriately normal (in up to $30 \%$ ) $^{7}$ in the setting of hypercalcaemia. ${ }^{8}$ There are two other disorders in which hypercalcaemia is associated with elevated or normal PTH - tertiary hyperparathyroidism and familial hypocalciuric hypercalcaemia $(\mathrm{FHH})$.

Tertiary hyperparathyroidism occurs when PTH increases to maintain normocalcaemia in the setting of vitamin D deficiency; eventually parathyroid hyperplasia occurs and PTH secretion becomes independent of calcium levels. This is commonly seen in chronic kidney disease.

$\mathrm{FHH}$ is a disorder caused by mutations in the calcium-sensing receptor gene. ${ }^{6}$ A 24 -hour urinary calcium or a calcium:creatinine excretion ratio can help identify these patients - calcium excretion is low in FHH. Genetic testing to detect mutations directly in CaSR is also now available. ${ }^{9}$ It is important to distinguish $\mathrm{FHH}$ from primary hyperparathyroidism as FHH does not require surgical intervention.

\section{Key points}

Hypercalcaemia is most commonly caused by primary hyperparathyroidism or malignancy

Measuring parathyroid hormone levels is most important in deciphering the underlying diagnosis

Classical symptoms of hypercalcaemia become more apparent as serum calcium concentrations approach $3 \mathrm{mmol} / \mathrm{l}$ or if a rise occurs over a short duration

The first step in the management of severe hypercalcaemia is the restoration of euvolaemia

Subsequent treatment of hypercalcaemia is most effective if directed at the underlying pathology

KEY WORDS: Hypercalcaemia, vitamin D, hyperparathyroidism, malignancy, bisphosphonates

Table 1. Symptoms and signs associated with hypercalcaemia.

\begin{tabular}{ll} 
Symptoms & Signs \\
Fatigue or lethargy & Altered mental state \\
Confusion & Polyuria (if diabetes insipidus) \\
Thirst & Oliguria (if acute kidney injury) \\
Muscle pain & Renal angle tenderness or haematuria (if renal calculi) \\
Abdominal pain & Myopathy \\
Nausea or vomiting & Reduced bowel sounds \\
Anorexia & Arrhythmia (also demonstrates short QT interval on ECG) \\
Constipation & Dehydration \\
Palpitations & Band keratopathy \\
\hline ECG = electrocardiography. &
\end{tabular}

Table 2. Clinical features of primary hyperparathyroidism compared to malignancy-associated hypercalcaemia.

$\begin{array}{lll}\text { Features of presentation } & \text { Primary hyperparathyroidism } & \text { Malignancy-associated } \\ \text { Duration of hypercalcaemia } & \text { Often long-standing } & \text { Acute or subacute } \\ \text { Patient status } & \text { Relatively well } & \text { Unwell } \\ \text { Serum calcium } & \text { Usually }<3.0 \mathrm{mmol} / \mathrm{I} & \text { Can be }>3.5 \mathrm{mmol} / \mathrm{l} \\ \begin{array}{l}\text { Evidence of underlying } \\ \text { malignancy }\end{array} & \text { No } & \begin{array}{l}\text { Often detected in patients with } \\ \text { known malignancy - can be first } \\ \end{array} \\ & & \begin{array}{l}\text { presentation } \\ \end{array}\end{array}$

Most patients with primary hyperparathyroidism are diagnosed when hypercalcaemia is identified during blood tests for unrelated clinical indications. ${ }^{10}$ It is now rare for primary hyperparathyroidism to present with 'classical' symptoms and quantitatively severe hypercalcaemia (serum calcium $>3.5 \mathrm{mmol} / \mathrm{l}){ }^{10}$

\section{Hypercalcaemia with suppressed PTH}

In malignancy-associated hypercalcaemia, PTH is suppressed. Hypercalcaemia of malignancy occurs in about $25 \%$ of cancer patients and can be caused by a number of different mechanisms outlined in Box $1 .^{5}$

Granulomas express the $1 \alpha$-hydroxlase enzyme that activates vitamin $\mathrm{D}$, causing excessive calcium absorption, which in turn appropriately suppresses PTH secretion. When the origin of hypercalcaemia is unclear, measurement of 1,25- $(\mathrm{OH})_{2}$ vitamin $\mathrm{D}$ can help to identify increased conversion of $25-\mathrm{OH}$ vitamin D to $1,25-(\mathrm{OH})_{2}$ vitamin D. There is no other clinically useful application for measuring $1,25-(\mathrm{OH})_{2}$ vitamin $\mathrm{D}$.

\section{Treatment of hypercalcaemia}

There are a number of considerations when making treatment decisions (Box 2).

\section{Emergency management of hypercalcaemia}

The first intervention in severe hypercalcaemia $(>3.5 \mathrm{mmol})$ or in symptomatic individuals is always restoration of euvolaemia. Intravenous normal saline at rates of up to $500 \mathrm{ml} / \mathrm{h}$ can be required and the patient's underlying co-morbidities should be considered when prescribing the rate of infusion. ${ }^{4}$ Less than $30 \%$ of patients achieve normocalcaemia with fluids alone. ${ }^{5}$ Bisphosphonates are considered after fluid replacement (see section on excess bone resorption below). It is important to make sure blood has been tested for PTH level before giving bisphosphonates as they can alter serum PTH levels and give misleading PTH results. Subcutaneous or intramuscular calcitonin can achieve a rapid lowering of serum calcium through increased renal excretion, but beware of rebound hypercalcaemia. Life-threatening hypercalcaemia is an indication that haemodialysis should be 
considered..$^{5}$ Early or semi-urgent parathyroidectomy might be performed in severe primary hyperparathyroidism or even in the second trimester of pregnancy if indicated. ${ }^{12}$

\section{Primary hyperparathyroidism}

Parathyroidectomy is the only definitive treatment for primary hyperparathyroidism. ${ }^{10}$ All symptomatic patients should be considered for surgery. Asymptomatic patients should be considered for surgery if serum calcium is $\geqslant 0.25 \mathrm{mmol}$ above the upper limit of the reference range, if glomerular filtration rate (GFR) is $<60 \mathrm{ml} / \mathrm{min}$, if the T score is $<-2.5$ at any DXA scan site, if the patient has a history of previous fragility fracture, or if the patient age is $<50$ years of age. ${ }^{10}$ Some patients are unsuitable for or fail surgery; cinacalcet is licensed for these patients in the UK. Cinacalcet reduces PTH levels by acting on the CaSR. It is effective in lowering hypercalcaemia to $<2.57 \mathrm{mmol} / \mathrm{l}$ in $75 \%$ of patients with sustained effects over 5 years of treatment, but there is little evidence to date regarding end organ effects. ${ }^{8}$

\section{Hypercalcaemia secondary to excess bone resorption}

This group includes patients with malignancy-associated hypercalcaemia resulting from PTH-related protein secretion or osteolysis. ${ }^{4}$ Bisphosphonates are effective in hypercalcaemia secondary to bone resorption. ${ }^{5}$ A number of intravenous bisphosphonate preparations are licensed in the UK for hypercalcaemia of malignancy. Zolendronic acid might have a lower rate of relapse than other bisphosphonates. ${ }^{13}$ Denosumab is a biological anti-resorptive agent that is licensed for the prevention, but not treatment, of skeletal-related events including hypercalcaemia in solid tumours. ${ }^{5,14}$

\section{1,25-(OH) 2 vitamin D-induced hypercalcaemia}

Hypercalcaemia that is caused by this mechanism results from increased absorption of calcium from the gut, thus bisphosphonates are not useful. Tumours or granulomas that produce $1 \alpha$-hydroxylase might respond to steroid therapy. ${ }^{4}$

\section{Box 1. Causes of hypercalcaemia.}

- Primary hyperparathyroidism - sporadic (single adenoma) or associated with multiple endocrine neoplasia (hyperplasia)

- Malignancy ${ }^{5}$

- Humoral hypercalcaemia of malignancy, accounts for $80 \%$ of cases of hypercalcaemia, secondary to PTHrP secretion (PTHrP measurements are rarely justified to confirm the diagnosis) ${ }^{4}$

- Local osteolytic hypercalcaemia, secondary to osteoclast activation by cytokines from bone metastases

- 1,25-(OH $)_{2}$ vitamin D-induced hypercalcaemia, secondary to lymphomas that express $1 \alpha$-hydroxylase

- Sarcoidosis

- Tuberculosis

- Familial hypocalciuric hypercalcaemia (usually benign course) ${ }^{6}$

- Immobilisation

- Paget's disease

- Tertiary hyperparathyroidism - chronic kidney disease, vitamin D deficiency, some genetic disorders

- Associated with endocrine disorders

- Hyperthyroidism, acromegaly, phaeochromocytoma

- Drug-induced

- Thiazide diuretics

- Vitamin A or D excess

- Lithium

- Calcium-containing antacids 'milk-alkali syndrome' (rare since the advent of proton pump inhibitors)

1,25- $(\mathrm{OH})_{2}$ vitamin $\mathrm{D}=$ vitamin $\mathrm{D} ; \mathrm{PTHrP}=$ parathyroid hormone-related protein.

\section{Box 2. Approach to management of hypercalcaemia.}

- Achieve euvolaemia ${ }^{4,5}$

- Withhold diuretics

- Advise outpatients to maintain good fluid intake

- Infuse $0.9 \%$ saline solution as tolerated for those requiring in patient care

- Symptoms

- Treat if symptomatic, regardless of serum calcium level

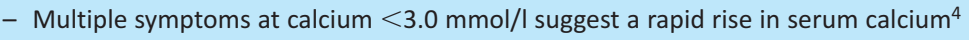

- Degree of hypercalcaemia

- Treat as an emergency if calcium is $>3.5 \mathrm{mmol} / \mathrm{l}$ (regardless of symptoms)

- Consider rapid lowering of calcium with calcitonin

- Consider haemodialysis if life-threatening

- Co-morbidities

- Caution should be taken with fluid replacement in the setting of cardiac failure or renal failure

- Furosemide can be used if there is volume overload, but should not be used primarily to treat hypercalcaemia ${ }^{11}$

- Caution should be taken with bisphosphonates

- In chronic kidney disease

- consider dose reduction or slower infusion - seek expert opinion

- In presence of vitamin D deficiency

- the hypocalcaemia might ensue, even in setting of initial hypercalcaemia

- Underlying mechanism of hypercalcaemia

- Ask about drugs and diet (thiazides frequently implicated); stop offending agent if possible

- Treat hypercalcaemia based on underlying disease, if known -

- Surgery for primary or tertiary hyperparathyroidism

- Bisphosphonates in cases of increased bone resorption

- Steroids in granulomatous disease or lymphoma (if diagnosis secure)

- Treat underlying disease (see above)

- Surgery, chemotherapy or radiotherapy in malignancy

- Steroids or disease-modifying agents in sarcoidosis

- Anti-tuberculous drugs in tuberculosis 


\section{Summary}

The management of patients with hypercalcaemia should be informed by the patient's symptoms and signs, by the degree of elevation of calcium, by the underlying mechanism by which calcium has been elevated and by the disease process underlying the presentation. Regardless of diagnosis, all significantly hypercalcaemic patients should be rendered euvolaemic before any further and more specific treatment is considered. Highly symptomatic patients and those with a calcium level of $>3.5 \mathrm{mmol}$ represent a medical emergency that requires inpatient treatment.

\section{References}

1 Favus MJ, Goltzman D. Regulation of calcium and magnesium. In: Rosen CJ (ed), Primer on the metabolic bone diseases and disorders of mineral metabolism. Washington DC: The American Society for Bone and Mineral Research, 2008:104-8.
2 Chen RA, Goodman WG. Role of the calcium-sensing receptor in parathyroid gland physiology. Am J Physiol Renal Physiol 2004;286:F1005-11.

3 Bustamante M, Hasler U, Leroy V et al. Calcium-sensing receptor attenuates AVP-induced aquaporin-2 expression via a calmodulin-dependent mechanism. J Am Soc Nephrol 2008;19:109-16.

4 Stewart AF. Clinical practice. Hypercalcemia associated with cancer. $N$ Engl J Med 2005;352:373-9.

5 McCurdy MT, Shanholtz CB. Oncologic emergencies. Crit Care Med 2012;40:2212-22.

6 Davies JH, Shaw NJ. Investigation and management of hypercalcaemia in children. Arch Dis Child 2012;97:533-8.

7 Rejnmark L, Amstrup AK, Mollerup CL et al. Further insights into the pathogenesis of primary hyperparathyroidism: a nested case-control study. J Clin Endocrinol Metab 2013;98:87-96.

8 Khan AA. Medical management of primary hyperparathyroidism. J Clin Densitom 2013;16:60-3.

9 Guarnieri V, Canaff L, Yun FH et al. Calcium-sensing receptor (CASR) mutations in hypercalcemic states: studies from a single endocrine clinic over three years. J Clin Endocrinol Metab 95:1819-29.
10 Bilezikian JP, Khan AA, Potts JT Jr. Guidelines for the management of asymptomatic primary hyperparathyroidism: summary statement from the third international workshop. J Clin Endocrinol Metab 2009;94:335-9.

11 LeGrand SB, Leskuski D, Zama I. Narrative review: furosemide for hypercalcemia: an unproven yet common practice. Ann Intern Med 2008;149:259-63.

12 Cooper MS. Disorders of calcium metabolism and parathyroid disease. Best Pract Res Clin Endocrinol Metab 2011;25:975-83.

13 Legrand SB. Modern management of malignant hypercalcemia. Am J Hosp Palliat Care 2011;28:515-7.

14 Brown-Glaberman U, Stopeck AT. Role of denosumab in the management of skeletal complications in patients with bone metastases from solid tumors. Biologics 2012;6:89-99.

\section{Address for correspondence:}

Dr N Gittoes, Department of Medicine, Old Queen Elizabeth Hospital, Edgbaston, Birmingham B15 2TH.

Email: neil.gittoes@uhb.nhs.uk

\section{Need support in your daily work on the AMU?}

Then try our acute care toolkits, a series of free resources designed to improve the delivery of acute care. Between four and six pages long, the toolkits cover clinical and service delivery issues, summarising the latest guidance and providing practical tips on ways to improve quality of care. Ensure your patients get the highest quality acute medical care-access the toolkits today.

Available at: www.rcplondon.ac.uk/resources/acute-care-toolkits
Topics covered by the toolkits are:

$>$ handover

$>$ high-quality acute care

$>$ acute medical care for frail older people

> delivering a 12-hour, 7-day consultant presence on the acute medical unit > teaching on the acute medical unit. 